\title{
Reasoning with deontic and counterfactual conditionals
}

\author{
Ana Cristina Quelhas \\ Instituto Superior de Psicologia Aplicada, Portugal \\ Ruth M.J. Byrne \\ University of Dublin, Trinity College, Ireland
}

\begin{abstract}
We report two new phenomena of deontic reasoning: (1) For conditionals with deontic content such as, "If the nurse cleaned up the blood then she must have worn rubber gloves", reasoners make more modus tollens inferences (from "she did not wear rubber gloves" to "she did not clean up the blood") compared to conditionals with epistemic content. (2) For conditionals in the subjunctive mood with deontic content, such as, "If the nurse had cleaned up the blood then she must have had to wear rubber gloves", reasoners make the same frequency of all inferences as they do for conditionals in the indicative mood with deontic content. In this regard, subjunctive deontics are different from subjunctive epistemic conditionals: reasoners interpret subjunctive epistemic conditionals as counterfactual and they make more negative inferences such as modus tollens from them. The experiments show these two phenomena occur for deontic conditionals that contain the modal auxiliary "must" and ones that do not. We discuss the results in terms of the mental representations of deontic conditionals and of counterfactual conditionals.
\end{abstract}

Most research on conditional inference has focused on conditionals in the indicative mood about factual possibilities, e.g., "if the woman washed the dishes

\footnotetext{
Address correspondence to Professor Ana Cristina Quelhas, Instituto Superior de Psicologia Aplicada, Rua Jardim do Tabaco, 34, 1149-041 Lisboa, Portugal. Email: cquelhas@ ispa.pt

We thank Aidan Feeney, Vittorio Girotto, Phil Johnson-Laird, Ken Manktelow, and David Over for helpful comments on an earlier draft. We are also grateful to Mark Keane, Juan GarciaMadruga, Sergio Moreno-Rios, Alessandra Tasso, and Valerie Thompson for discussions of counterfactuals. We thank the Portuguese Foundation for Science and Technology (FCT), for supporting this research through the European programmes PRAXIS and POCTI. Some of the results were presented at the workshop on Mental Models in Reasoning in Madrid in 1998, the European Conference on Cognitive Science in Siena in 1999, the International Thinking conference in Durham in 2000, and the Cognitive Processes and Context in Counterfactuals meeting in Lisbon in 2002.
}

(C) 2003 Psychology Press Ltd

http://www.tandf.co.uk/journals/pp/13546783.html

DOI: $10.1080 / 13546780244000105$ 
then she wore rubber gloves" (for a review see Evans, Newstead, \& Byrne, 1993). But recent attention has focused on two major categories of non-indicative conditionals: deontic conditionals that refer to permissions and obligations, e.g., "if the nurse cleaned up the blood then she must have worn rubber gloves" (e.g., Manktelow \& Over, 1990), and subjunctive conditionals that refer to counterfactual situations that were once possible but are so no longer, e.g., "if the car had run out of petrol then it would have stalled" (Byrne \& Tasso, 1999; Thompson \& Byrne, in press). Our aim in this paper is to examine conditionals that are both deontic and subjunctive, e.g., "If the nurse had cleaned up the blood then she must have had to wear rubber gloves".

Deontic subjunctives seem to be different from epistemic subjunctives. Rephrasing an epistemic conditional, e.g., "if the woman washed the dishes then she wore rubber gloves" using the subjunctive mood, e.g., "if the woman had washed the dishes then she would have worn rubber gloves", tends to make it counterfactual (Byrne \& Tasso, 1999; Thompson \& Byrne, in press). Many epistemic subjunctives communicate a situation that was once possible but is so no longer. People understand that the factual possibilities conjectured in the antecedent and consequent of the conditional are false, and in fact the woman did not wash the dishes and she did not wear rubber gloves. But does rephrasing a deontic conditional, "if the nurse cleaned up the blood then she must have worn rubber gloves" using the subjunctive mood, "if the nurse had cleaned up the blood then she must have had to wear rubber gloves" make it counterfactual? We suggest not. The deontic subjunctive may convey that the factual possibility conjectured in the antecedent of the conditional is false, and in fact the nurse did not clean up the blood. But it does not convey that the deontic possibilities conjectured in the consequent are false, and that in fact the nurse did not have to wear rubber gloves; nor does it convey that the factual possibilities are false, and that in fact she did not wear rubber gloves. We first report the results of two experiments that corroborate this novel claim. We then suggest that shared knowledge or context is essential for a deontic subjunctive to communicate that a situation once was (or was not) permissible or obligatory and is so no longer, e.g., "if you had gone to school 50 years ago, you would have had to learn Latin".

\section{INDICATIVE CONDITIONALS}

People readily make inferences from conditionals in the indicative mood. Most people make the valid modus ponens (MP) inference, from "she washed the dishes" to "she wore rubber gloves". They have difficulty in making the valid modus tollens (MT) inference, from "she did not wear rubber gloves" to "she did not wash the dishes". Instead they often say that nothing follows. The frequency with which they make the affirmation of the consequent (AC) inference (from "she wore rubber gloves" to "she washed the dishes") and the denial of the antecedent (DA) inference (from "she did not wash the dishes" to "she did not 
wear rubber gloves") varies in different studies (Evans et al., 1993), although AC tends to be made somewhat more than DA (Johnson-Laird \& Byrne, 2002).

Why are some inferences easy and others hard? According to one view, people understand a conditional in the indicative mood such as, "if the woman washed the dishes then she wore rubber gloves", by keeping in mind explicitly just one true possibility:

washed gloves

where "washed" represents "she washed the dishes", and "gloves" represents "she wore rubber gloves", and separate models are represented on separate lines in the diagram (Johnson-Laird \& Byrne, 1991). People are aware that there are alternative possibilities, and the three dots represent an implicit model, which indicates that alternatives to the explicit model exist but they have not been represented explicitly (Johnson-Laird, Byrne, \& Schaeken, 1992). The initial set of models is economical because of the constraints of working memory. MP is easy because it can be made from the initial set of models, but MT is more difficult because "she did not wear rubber gloves" cannot be matched to the information represented explicitly in the initial set of models. It requires the models to be fleshed out to represent other true possibilities, e.g:

$\begin{array}{ll}\text { washed } & \text { gloves } \\ \text { not-washed } & \text { not-gloves }\end{array}$

where "not" is a propositional-like tag to represent negation (Johnson-Laird \& Byrne, 1991). The interpretation of conditionals is mediated by their content and context (Byrne, Espino, \& Santamaria, 1999; Johnson-Laird \& Byrne, 2002). The models may be fleshed out beyond this "biconditional" interpretation to include a third possibility:

$\begin{array}{ll}\text { washed } & \text { gloves } \\ \text { not-washed } & \text { not-gloves } \\ \text { not-washed } & \text { gloves }\end{array}$

Regardless of the interpretation, the information from the minor premise "she did not wear rubber gloves" leaves only the second model and the conclusion that "she did not wash the dishes" can be made. MP requires a single explicit model to be kept in mind, whereas MT requires more than one explicit model to be kept in mind, and inferences that require multiple models are more difficult than those that require a single model, as many studies have shown (Johnson-Laird \& Byrne, 1991). 


\section{COUNTERFACTUAL CONDITIONALS}

Conditionals can refer to counterfactual possibilities as well as to factual possibilities, that is, they can refer to situations that once were factual possibilities, but that did not occur (e.g., Johnson-Laird \& Byrne, 2002). People can readily generate counterfactuals (Kahneman \& Miller, 1986) and their counterfactuals tend to focus on similar events, such as actions (Byrne \& McEleney, 2000; Kahneman \& Tversky, 1982), controllable events (Girotto, Legrenzi, \& Rizzo, 1991; McCloy \& Byrne, 2000), the most recent event (Byrne, Segura, Culhane, Tasso, \& Berrocal, 2000; Miller \& Gunesagerem, 1990), or the first cause (Wells, Taylor, \& Turtle, 1987; Segura, Fernandez-Berrocal, \& Byrne, 2002). Counterfactuals are often phrased in the subjunctive mood and often refer to a close alternative (e.g., Lewis, 1973; Stalnaker, 1968).

People may understand a counterfactual, such as, "if the woman had washed the dishes then she would have worn rubber gloves" by keeping in mind two possibilities from the outset: the conjecture, the woman washed the dishes and she wore rubber gloves, and the presupposed facts, the woman did not wash the dishes and she did not wear rubber gloves:

$\begin{array}{lll}\text { factual: } & \text { not-washed } & \text { not-gloves } \\ \text { counterfactual: } & \text { washed } & \text { gloves }\end{array}$

The counterfactual requires reasoners to represent what is false, temporarily supposed to be true, and they may tag their models to keep track of their epistemic status, as indicated by the tags "factual" and "counterfactual" in the diagram (Johnson-Laird \& Byrne, 1991). When people are given a counterfactual, their memory tends to be that they were given instead the facts "she did not wash the dishes" and "she did not wear rubber gloves" (Fillenbaum, 1974). They judge that someone uttering the counterfactual means to imply these facts (Thompson \& Byrne, in press). They can more readily make the MT and DA inferences that require access to the facts (Byrne \& Tasso, 1999). For example, given, "she did not wear rubber gloves", reasoners do not have to flesh out their models to make the MT inference, they can incorporate the information directly into the initial set of models.

The subjunctive mood can act as a cue that the antecedent and consequent are false, but mood is an imperfect cue; it is neither necessary (Dudman, 1988) nor sufficient (Thompson \& Byrne, in press). Content and context can help in the interpretation of counterfactuality. People are more inclined to keep the facts in mind for a causal counterfactual such as, "if the car had been out of petrol then it would have stalled" than for a definitional counterfactual such as "if the animal had been a robin then it would have been a bird" (Thompson \& Byrne, in press). 
A subjunctive conditional such as, "if there had been deserters at Waterloo they would have been shot" may be interpreted as a counterfactual in a context in which it is clear that there were no deserters, but it may be interpreted as a hypothetical conditional in a context in which the speaker and hearer do not know whether there were deserters or not (Johnson-Laird \& Byrne, 2002).

The subjunctive mood can also be used for "semi-factual" conditionals, such as, "even if the woman had washed the dishes she still would have worn rubber gloves" (McCloy \& Byrne, 2002). People understand the semifactual by keeping in mind the conjecture, she washed the dishes and wore rubber gloves, and the facts, this time that she didn't wash the dishes and yet she wore rubber gloves:

$\begin{array}{lll}\text { factual: } & \text { not-washed } & \text { gloves } \\ \text { counterfactual: } & \text { washed } & \text { gloves }\end{array}$

Semifactuals convey that their antecedents are false but their consequents true, and access to these facts ensures that reasoners make fewer of the DA and AC inferences from semifactuals (Moreno-Ríos, García-Madruga, \& Byrne, 2002). In fact, given the DA premise "she did not wash the dishes" they often conclude "she wore gloves" (Moreno-Ríos et al., 2002).

\section{DEONTIC CONDITIONALS}

Conditionals can refer to what is permissible as well as to what is possible. People reason well with deontic conditionals, e.g., "if the nurse cleans up blood [it is obligatory that] she wears rubber gloves" (e.g., Manktelow \& Over, 1990). For example, in Wason's selection task, participants are given four cards corresponding to four instances, e.g., a nurse cleaning up blood, a nurse not cleaning up blood, a nurse wearing rubber gloves, and a nurse not wearing rubber gloves, and they correctly select the cards that test the rule, the "cleaning up blood" card and the "not wearing gloves" card (e.g., Manktelow \& Over, 1991).

The antecedent of the deontic conditional refers to a factual possibility and the consequent to a deontic possibility (Johnson-Laird \& Byrne, 2002). Knowledge of some deontic rules may ensure that reasoners know not only what is permissible, but also what is not permissible, e.g., a nurse cleaning up blood without wearing gloves (Johnson-Laird \& Byrne, 2002). Reasoners could use their knowledge to construct fully explicit models of the true possibilities, e.g:

$\begin{array}{llll}\text { Factual possibilities: } & \text { blood } & \text { gloves } & \text { :Deontic possibilities } \\ & \text { not-blood } & \text { gloves } & \\ & \text { not-blood } & \text { not-gloves } & \end{array}$


and their knowledge also provides the complement of these models:

Factual possibility: blood not-gloves :Deontic impossibility

In fact, they may construct an initial set of models of the following sort:

\begin{tabular}{|c|c|c|c|}
\hline Factual possibilities: & blood & gloves & :Deontic possibilities \\
\hline actual possibility: & blood & not-gloves & :Deontic im \\
\hline
\end{tabular}

They can use the complementary model to help them select the cards that can violate the rule (Johnson-Laird \& Byrne, 2002). The key principles underlying the proposed representation are (a) reasoners represent true possibilities, e.g., the nurse cleans blood and must wear gloves, but because of working memory constraints, they do not represent all of the true possibilities in their initial representation (Johnson-Laird \& Byrne, 1991), and (b) semantic or pragmatic modulation can lead reasoners to represent counterexamples directly, e.g., she cleans up blood and does not wear gloves is not permissible (Johnson-Laird \& Byrne, 2002). Knowledge can make a counterexample explicitly available (e.g., Griggs \& Cox, 1983). Of course familiarity with the rule is not essential: knowledge of the context or the linguistic expression (e.g., a modal auxilliary such as "must") can cue the need to represent what is impermissible for unfamiliar plausible deontic rules (e.g., Girotto, Gilly, Blaye, \& Light, 1989), and even for abstract deontic rules (e.g., Cheng \& Holyoak, 1985; Girotto, Mazzocco, \& Cherubini, 1992). A deontic conditional unlike a factual conditional is not false in the case in which the nurse cleaned up blood and did not wear rubber gloves. The deontic conditional may still be true but the nurse violated its obligation (see Johnson-Laird \& Byrne, 2002). Of course, a deontic conditional can be false in some circumstances, e.g., in a country where it is not in fact obligatory for nurses to wear rubber gloves to clean up blood. In fact, reasoners select different cards in a selection task that requires them to test whether a deontic rule is obeyed or is in force (Girotto, Kemmelmeier, Sperber, \& Van der Henst, 2001).

Most research on deontic conditionals has been with the selection task, and our aim is to provide a systematic comparison of the frequency with which adults make the four conditional inferences from deontic contents (for an examination of MP and DA, see Manktelow \& Fairley, 2000). Our account leads to a novel set of predictions about the relative frequencies of the four inferences from deontic and epistemic conditionals:

Prediction 1: We expect that reasoners should make more MT inferences from deontic conditionals, because they have access in their initial set of models to what is not permissible. When they are told that the nurse is not wearing gloves, they can match this information to the information in their models of the deontic 
impossibility, and they can infer that it is not permissible for her to clean up blood. Our account implies that MT can be made in either of two ways. One way is from the representation of the true possibilities, e.g., the possibility that the nurse did not clean blood and did not wear gloves. When it is known that the nurse did not wear gloves, it can be inferred that the nurse did not clean blood. This route may be most common for MT from epistemic conditionals, and it requires the models to be fleshed out to include this possibility explicitly. A second route for MT is via the representation of what is impossible. The nurse cleaning blood and not wearing gloves is represented as an impossibility. When it is known that the nurse did not wear gloves, the impossibility of the nurse cleaning blood can be inferred. This route is available for deontic conditionals when what is impossible is represented explicitly from the outset. Hence we predict that reasoners should make more MT inferences from deontic conditionals because they can avail themselves of this second route.

Of course, these two routes are available for the other inferences, e.g., MP can also be made in these two ways. But we do not predict any difference in modus ponens inferences from deontic and epistemic conditionals, because both have ready access to the "true possibilities" route to MP. They should make the same amount of MP, and of AC, inferences because they have represented in their initial set of models the affirmative possibility (the nurse cleans up blood and wears gloves). We also expect that they should not make more of the DA inferences: there is no direct match in the initial set of models to the information "the nurse did not clean up the blood" and so the models must be fleshed out further to incorporate this information, just as they must for an epistemic conditional. In fact, given that with deontic conditionals reasoners already have two models in mind, they may find it especially difficult to flesh out their models to include a third model.

\section{SUBJUNCTIVE DEONTIC CONDITIONALS}

Deontic conditionals can be phrased not only in the indicative mood but also in the subjunctive, e.g., "if the nurse had cleaned up the blood then she must have had to wear rubber gloves", and they can use a variety of modal auxiliaries, some of which make the obligatory nature of the consequent explicit, “...she would have had to have worn rubber gloves" or "she must have had to wear rubber gloves", and others which leave it implicit, e.g., "... she would have worn rubber gloves", or do not disambiguate between its deontic or epistemic status, e.g., "...she must have worn rubber gloves". A subjunctive epistemic is usually interpreted as counterfactual: the antecedent and consequent are false. But we suggest that a subjunctive deontic, "if the nurse had cleaned up the blood then she must have had to wear rubber gloves" does not convey counterfactuality: it may convey that the antecedent is false, but not that the consequent is false; it does not convey that the nurse did not have to wear rubber gloves, nor that she did not 
wear them. Accordingly, a subjunctive deontic may be represented in exactly the same way as an indicative deontic, that is, with two explicit models corresponding to what is permissible and what is not permissible. Reasoners do not construct a model from the outset corresponding to the presupposed facts (the not-p and not-q possibility), as they do for a subjunctive epistemic. Our account leads to a novel set of predictions about the relative frequencies of the four inferences from indicative and subjunctive deontic conditionals:

Prediction 2: For deontic content we predict that people will make MT and DA as often from a subjunctive as from an indicative conditional. In contrast, for conditionals based on epistemic content, people are more readily able to make MT and DA inferences from a subjunctive than an indicative conditional (Byrne \& Tasso, 1999). Recall that we predicted that the frequency of MT should be high for an indicative deontic; we predict it should be equally high for a subjunctive deontic, because we propose there is no difference in the representation of indicative and subjunctive deontic conditionals. (Note that we do not make an additive prediction: we do not expect any increase in MT to accrue for subjunctive deontics over indicative deontics, because the subjunctive mood does not confer any greater access to the not-p and not-q case for deontics as it does for epistemics.) MT should be made more often from both the indicative and subjunctive deontics than from the indicative epistemic; MT should be made as often from both deontics as from the epistemic subjunctive.

Recall that we predicted the frequency of DA should be low for an indicative deontic; we predict it should be equally low for a subjunctive deontic, because the representations are the same. DA should be made no more often from the indicative and subjunctive deontics than from the indicative epistemic; DA should be made less often from both deontics (and the indicative epistemic) than from the subjunctive epistemic. Our suggestions about the representation of indicative and subjunctive deontic conditionals, lead us to believe that there should be no differences for MP and AC.

\section{EXPERIMENT 1 \\ SUBJUNCTIVE DEONTIC AND EPISTEMIC CONDITIONALS}

We examined indicative deontic conditionals, e.g., "if he drove the car then he fastened the seat belt", and subjunctive deontics, e.g., "if he had driven the car then he would have fastened the seat belt", and we compared them to indicative epistemic conditionals, e.g., "if Ana was in Coimbra then Joao was in Lisboa", and subjunctive epistemics, e.g., "if Ana had been in Coimbra then Joao would have been in Lisboa". The deontic content we used was based on familiar regulations that currently apply for driving (see the Appendix), concerning obligations to wear a seatbelt, to turn on headlights at night, to drive at certain 
speeds on the motorway, and not to drink alcohol and drive. We chose this content because it concerned social and legal regulations that could be expected to be very well known to our participants.

\section{Method}

Materials and design. The content of the conditionals was either epistemic (people in places) or deontic (driving regulations) and they were phrased in either the indicative or subjunctive mood (see the Appendix for the set of materials). The materials were presented to the participants in their native Portuguese. The experiment had one between-subjects factor, conditional type, either indicative or subjunctive, and so there were two groups of participants. The two withinsubject factors were the content type, epistemic or deontic, and the four inference types, modus ponens, modus tollens, denial of the antecedent, and affirmation of the consequent. The design was thus a 2 by 2 by 4 mixed factorial, with repeated measures on the second two factors. Each participant carried out 32 inferences, four instances of each of the four inferences for each of the two contents. The dependent variables were the conclusion selected, and the latency to choose the conclusion.

Procedure. Participants carried out eight practice problems (two conditionals based on shapes, with each of the four inferences) to familiarise them with the presentation of materials in the SUPERLAB program on a PC. The 32 arguments were then presented in a different random order for each participant. The participants pressed a key to see the conditional premise on screen, then they pressed a key to see the second premise which joined the conditional on the screen, and finally they pressed a key to see the selection of conclusions which joined the premises on the screen. The conclusions were presented in the same fixed order for all problems, e.g: (1) He fastened the seat belt, (2) He did not fasten the seat belt, (3) He may or may not have fastened the seat belt. Participants were told that there was no time limit, and they chose a conclusion by pressing the number keys, 1,2 , or 3 , corresponding to their conclusion choice. The latency to choose the conclusion was the recorded time from the presentation of the conclusion on screen, controlled by the participant's key press, to the selection of a response, also controlled by the participant's key press.

Participants. The participants were 72 undergraduate students from Lisbon's Instituto Superior de Psicologia Aplicada. The participants were 9 men and 63 women, with an average age of 19 (SD 2.73). They were assigned at random to the two conditions, indicative $(n=34)$, and subjunctive $(n=38)$. 


\section{Results}

The results corroborated both sets of predictions, as Table 1 shows. For indicative conditionals, participants made more MT inferences from deontic than epistemic content, $68 \%$ vs $46 \%, F(1,70)=11.88, p<.0000$. There were no reliable differences in the frequency of DA inferences, $51 \%$ vs $61 \%, F(1,70)=$ $2.26, p<.14$, MP inferences, $92 \%$ vs $88 \%, F(1,70)=0.98 p<.32$, and AC inferences, $68 \%$ vs $70 \%, F(1,70)=0.11, p<.74$.

Second, there were no differences between subjunctive and indicative conditionals for the deontic content for any of the inferences: MT, $74 \%$ vs $68 \%$, $F(1,70)=0.64, p<.43$; DA, 54\% vs $51 \%, F(1,70)=0.97, p<.76$; MP, $90 \%$ vs $92 \%, F(1,70)=0.31, p<.58$; and AC, $53 \%$ vs $68 \%$, although the latter was marginal, $F(1,70)=3.37, p<.07$. Third, we replicated the higher frequency of MT and DA for subjunctives with epistemic content. Participants made more MT from the subjunctive than the indicative for epistemic content, $66 \%$ vs $46 \%$, $F(1,70)=4.71, p<.03$, and more DA, $78 \%$ vs $61 \%$, although the latter was marginal, $F(1,70)=3.01, p<.09$. There were no differences for MP, $95 \%$ vs $88 \%, F(1,70)=1.61, p<.21$, and $\mathrm{AC}, 64 \%$ vs $70 \%, F(1,70)=0.42, p<.52) .{ }^{1}$

TABLE 1

The percentages of endorsements of inferences for indicative and subjunctive conditionals based on epistemic and deontic content in Experiment 1

\begin{tabular}{lcccc}
\hline & $M P$ & $A C$ & $M T$ & $D A$ \\
\hline $\begin{array}{l}\text { Epistemic } \\
\text { Indicative }\end{array}$ & 88 & 70 & 46 & 61 \\
Subjunctive & 95 & 64 & 66 & 78 \\
Deontic & & & & \\
Indicative & 92 & 68 & 68 & 51 \\
Subjunctive & 90 & 53 & 74 & 54 \\
\hline
\end{tabular}

$\mathrm{MP}=$ modus ponens, $\mathrm{AC}=$ affirmation of the consequent, $\mathrm{MT}=$ modus tollens, $\mathrm{DA}=$ denial of the antecedent.

\footnotetext{
${ }^{1}$ These eight comparisons were computed by planned simple effects $t$-tests on the nonsignificant three-way interaction, $F(3,210)=0.72, p<.54$ (see Winer, 1971, for the legitimacy of such comparisons), on a 2 (factual, counterfactual) by 2 (epistemic, deontic) by 4 (MP, AC, DA, MT) ANOVA with repeated measures on the last two factors, on the endorsements of conclusions. The ANOVA showed a main effect of inference, $F(3,210)=28.98, p<.0000$, but not of content or conditional. Each of the three factors interacted, conditional and content, $F(1,70)=5.37, p<.02$, conditional and inference, $F(3,210)=3.89, p<.00$, and content and inference, $F(3,210)=12.94$, $p<.0000$.
} 
The relative frequency of MT for the four sorts of conditionals is as we expected. Participants made equally high frequencies of MT for the subjunctive and indicative deontics as we have seen (74\% and 68\%), and they made more MT from the indicative deontic than epistemic (68\% vs $46 \%)$. Participants made a high frequency of MT from the subjunctive deontic and epistemic and so there was no difference between them, $74 \%$ vs $66 \%, F(1,70)=1.34, p<.25$. In other words, as we predicted, all three $(74 \%, 68 \%$, and $66 \%)$ are higher than MT from the indicative epistemic (46\%). Participants made equally low frequencies of DA for the indicative deontic and epistemic as we have seen (51\% and $61 \%)$, and they made more DA from the subjunctive than the indicative epistemic (78\% vs $61 \%$ ). Participants made a lower frequency of DA from the subjunctive deontic than the subjunctive epistemic, $54 \%$ vs $78 \%, F(1,70)=15.51, p<.00$. In other words, as we predicted, all three $(54 \%, 51 \%$, and $61 \%)$ are lower than DA from the subjunctive epistemic (78\%). There were no reliable differences for the subjunctive deontic and epistemic for MP or AC, although the latter was marginal, $F(1,70)=2.24$ and $3.2, p<.14$ and .08 respectively. These results corroborate our suggestions about the representation of deontic conditionals in terms of what is permissible and what is not permissible.

The latencies to endorse the conclusions show that participants took the same length of time to make the MP, AC, and MT inferences, from subjunctives and indicatives, for deontic and epistemic content, as Table 2 shows. $^{2}$ The only reliable difference was that they took less time to endorse the conclusion for DA from subjunctives than indicatives, for both the epistemic, 8.3 vs $8.6, F(1,37)=$ $4.59, p<.03$, and deontic content, 8.2 vs $8.7, F(1,37)=4.55, p<.04$.

The experiment reveals two new phenomena of deontic reasoning: First the results show that reasoners make more MT inferences from deontic conditionals than from epistemic conditionals. The result corroborates our suggestion that a deontic conditional is represented in an initial set of models that makes explicit what is permissible and what is not permissible. The nurse cleaning blood and not wearing gloves is represented as an impossibility. When it is known that the nurse did not wear gloves, the impossibility of the nurse cleaning blood can be inferred. The results also show that reasoners make the same amount of MP, AC, and DA inferences from deontic as from epistemic conditionals. They make the same amount of MP and AC inferences because they have represented in their initial set of models the affirmative possibility (the nurse cleans up blood and wears gloves). For the DA inference, there is no direct match in the initial set of

\footnotetext{
${ }^{2}$ These eight comparisons were computed by simple effects $t$-tests on the non-significant threeway interaction, $F(3,111)=0.71, p<.55$, in an ANOVA on the log-transformed latencies for endorsements of conclusions. The ANOVA showed a main effect of content, $F(1,37)=8.11$, $p<.00$, and inference, $F(3,111)=4.72, p<.00$, but not of conditional. Content and inference interacted, $F(3,111)=3.62, p<.02$, but none of the other factors did.
} 
TABLE 2

The log-transformed latencies (ms) to endorse the conclusions for indicative and subjunctive conditionals based on epistemic and deontic content in Experiment 1

\begin{tabular}{lcccr}
\hline & $M P$ & $A C$ & $M T$ & $D A$ \\
\hline $\begin{array}{l}\text { Epistemic } \\
\text { Indicative }\end{array}$ & 8.372 & 8.154 & 8.443 & 8.598 \\
Subjunctive & 8.213 & 8.332 & 8.444 & 8.285 \\
Deontic & & & & \\
Indicative & 8.346 & 8.551 & 8.601 & 8.737 \\
Subjunctive & 8.130 & 7.883 & 8.555 & 8.205 \\
\hline
\end{tabular}

$\mathrm{MP}=$ modus ponens, $\mathrm{AC}=$ affirmation of the consequent, $\mathrm{MT}=$ modus tollens, $\mathrm{DA}=$ denial of the antecedent.

models to the information "the nurse did not clean up blood" for either sort of conditional, and so the models must be fleshed out further to incorporate it (e.g., to represent that the nurse does not clean up blood and does not wear rubber gloves) and so there is no difference between them. In fact, it may be especially difficult to flesh out the models any further for the deontic conditional given that reasoners must already keep two models in mind.

Second, the results show that reasoners make MT and DA as often from a deontic subjunctive as from a deontic indicative. For subjunctive epistemics, reasoners make more of the negative MT and DA inferences (Byrne \& Tasso, 1999; Thompson \& Byrne, in press). But for subjunctive deontics, they do not (see also Byrne \& Quelhas, 1999; Quelhas \& Byrne, 2000). The result corroborates our proposal that a subjunctive deontic is represented in the same way as an indicative deontic, by an initial set of models that makes explicit what is permissible and what is not permissible. A subjunctive deontic does not convey the presupposition that its antecedent and consequent are false.

Could the results simply indicate that the participants interpreted the conditionals differently, for example, understanding the deontic conditionals as biconditionals and the epistemic ones as conditionals? The data rule out this alternative explanation. The frequency of DA and AC, usually higher for biconditionals than conditionals, is in fact the same from the indicative deontic and epistemic (and even somewhat less from the deontic compared to the epistemic, AC 68\% and 70\%; DA 51\% and 61\%).

In the first experiment we conveyed the deontic nature of the conditionals without using explicit modals such as "must", or "should". In our next experiment, we examine the influence of such modal auxiliaries, by comparing inferences from deontic conditionals that contain "must" and those that do not. In addition, we use a wider range of contents for the deontic conditionals. Our aim is 
to replicate and generalise our results to subjunctive deontics that contain explicit modal auxiliaries.

\section{EXPERIMENT 2 SUBJUNCTIVE DEONTIC CONDITIONALS WITH MODALS}

Our aim in the second experiment was to compare indicative and subjunctive conditionals that rely on deontic content phrased with a modal auxiliary and without a modal. We examined indicative deontics with an explicit modal, e.g., "If the nurse cleaned up the blood then she must have worn rubber gloves" and subjunctive deontics with a modal, e.g., "If the nurse had cleaned up the blood then she must have had to wear rubber gloves". We compared them to indicative deontics without an explicit modal, e.g., "If the nurse cleaned up the blood then she wore rubber gloves", and subjunctive deontics without a modal, e.g., "If the nurse had cleaned up the blood then she would have worn rubber gloves". The deontic content we used was based on prudential obligations (Manktelow \& Over, 1990), such as obligations for nurses cleaning blood to wear rubber gloves, for motorcycle riders to wear helmets, and for tourists going deep sea diving to take a diving course (see the Appendix). We again included epistemic conditionals based on people-in-places content as a control comparison.

We chose the modal auxillary "must", because it is ambiguous between what is possible and what is permissible, and so it represents a strong test of our proposals about the representation of deontic content (if our predictions are supported even for "must" then we can infer they would be likely to be supported for the less ambiguous auxilliaries such as "should"). Our predictions are the same as in the previous experiment: first, we predict that reasoners will make more MT inferences from indicative deontic conditionals, either with or without a modal, compared to epistemic, and they will make the same amount of MP and $\mathrm{AC}$ and DA inferences; second we predict that reasoners will make MT and DA as often from a subjunctive as from an indicative conditional for deontic content, either with or without a modal.

\section{Method}

Materials and design. The conditionals were either indicative or subjunctive, and their content was either epistemic, deontic with a modal, or deontic with no modal (see the Appendix). There were six groups of participants: The first between-subjects factor was the conditional type, indicative or subjunctive, and the second between-subjects factor was the content type, epistemic, modal deontic, and non-modal deontic. They all carried out the four inference types, MP, AC, DA, MT, which was a within-subject factor. The design was thus a 2 by 3 by 4 mixed factorial design, with repeated measures on the last factor. The participants carried out three instances of each of the four 
inferences, and so each participant carried out 12 inferences. The dependent variables were the conclusion selected, and the latency to choose the conclusion.

Procedure. Participants carried out four practice problems with a neutral content to familiarise them with the presentation of the materials in the SUPERLAB program on a PC. They then received the 12 arguments in a different random order for each participant. The presentation was similar to the previous experiment, and there was a break of 1.5 seconds between each problem. Participants were told that there was no time limit, but that the time was measured. They chose a conclusion by pressing the number keys, 1, 2, or 3 .

Participants. The participants were 303 undergraduate students from Lisbon's Instituto Superior de Psicologia Aplicada. The participants were 51 men and 252 women, with an average age of 19 (SD 3.96). They were assigned at random to the conditions, indicative epistemic $(n=51)$, subjunctive epistemic $(n=50)$, indicative modal deontic $(n=52)$, subjunctive modal deontic $(n=49)$, indicative non-modal deontic $(n=52)$, and subjunctive non-modal deontic $(n=49)$.

\section{Results}

The results corroborated both sets of predictions, as Table 3 shows. First, for indicative conditionals, participants made more MT inferences from modal deontic than epistemic content, $76 \%$ vs $61 \%, F(1,297)=4.75, p<.03$, and somewhat more from non-modal deontic than epistemic, $72 \%$ vs $61, F(1,297)=$ $2.53, p<.11$ although the difference is not significant. They did not make more DA inferences from modal deontic compared to epistemic content, $51 \%$ vs $70 \%$, in fact reliably fewer, $F(1,297)=6.62, p<.01$, and they did not make more from non-modal deontic compared to epistemic, $65 \%$ vs $70 \%, F(1,297)=0.42, p<$ .52. There were no differences for MP or AC, as Table 3 shows. These results replicate the first experiment's results and extend them to deontic conditionals with an explicit modal auxiliary.

Second, as we predicted, for modal deontics, there were no differences between subjunctive and indicative conditionals for DA, $58 \%$ vs $51 \%, F(1,297)$ $=1.04, p<.30$, and MT, $78 \%$ vs $76 \%, F(1,297)=0.08, p<.77$, nor for MP, $87 \%$ vs $85 \%, F(1,297)=0.057, p<.81$ and AC, $52 \%$ vs $55 \%, F(1,297)=0.15, p<$ .698. Likewise, for non-modal deontics there were no differences between subjunctive and indicative conditionals for DA, $69 \%$ vs $65 \% F(1,297)=0.43$, $p<.51$, and MT, $80 \%$ vs $72 \%, F(1,297)=1.65, p<.198$, nor for MP, $89 \%$ vs $91 \%, F(1,297)=0.16, p<.688$, and AC, $71 \%$ vs $66 \%, F(1,297)=0.57, p<.44)$.

Third, we replicated the higher frequency of the negative inferences for subjunctives compared to indicatives for epistemic content. Participants made 
more DA from the subjunctive than the indicative conditionals, $83 \%$ vs $70 \%$, $F(1,297)=3.59, p<.059$; the difference for MT was small, however, $67 \%$ vs $61 \%, F(1,297)=0.63, p<.43$. There were no differences for MP, $90 \%$ vs $87 \%$, $F(1,297)=0.42, p<.52$, and $\mathrm{AC}, 68 \%$ vs $62 \%, F(1,297)=0.86, p<.35 .^{3}$

For subjunctive conditionals, participants made a high rate of MT from subjunctive modal deontic (78\%) and subjunctive non-modal deontic (80\%), even more than the high rate from the subjunctive epistemic, $67 \%, F(1,297)=$ $2.68, p<.10$ and $F(1,297)=4.19, p<.04$ respectively. In other words, as we expected, the frequency of MT was lowest from the indicative epistemic $(61 \%)$ compared to the three subjunctives $(78 \%, 80 \%$, and $67 \%$ ) and to the two indicative deontic conditionals $(76 \%$ and $72 \%)$. Participants made fewer DA inferences from the subjunctive conditionals for the subjunctive modal deontic $(58 \%)$ and subjunctive non-modal deontic $(69 \%)$ than from the subjunctive epistemic, $83 \%, F(1,297)=11.47, p<.00$ and $F(1,297)=3.46, p<.06$. In other words, as we expected, the epistemic subjunctive $(83 \%)$ was higher than the other two subjunctives $(58 \%, 69 \%)$ and the three indicatives $(70 \%, 51 \%, 65 \%)$. There were no systematic differences for MP or AC.

TABLE 3

The percentages of endorsements of inferences for indicative and subjunctive conditionals based on epistemic, modal deontic, and non-modal deontic content in Experiment 2

\begin{tabular}{lcccc}
\hline & $M P$ & $A C$ & $M T$ & $D A$ \\
\hline $\begin{array}{l}\text { Epistemic } \\
\text { Indicative }\end{array}$ & 87 & 62 & 61 & 70 \\
Subjunctive & 90 & 68 & 67 & 83 \\
$\begin{array}{l}\text { Deontic modal } \\
\text { Indicative }\end{array}$ & 85 & 55 & 76 & 51 \\
Subjunctive & 87 & 52 & 78 & 58 \\
Deontic non-modal & & & & \\
Indicative & 91 & 66 & 72 & 65 \\
Subjunctive & 89 & 71 & 80 & 69 \\
\hline
\end{tabular}

$\mathrm{MP}=$ modus ponens, $\mathrm{AC}=$ affirmation of the consequent, $\mathrm{MT}=$ modus tollens, $\mathrm{DA}=$ denial of the antecedent.

\footnotetext{
${ }^{3} \mathrm{We}$ carried out these 12 planned simple effects $t$-tests on the non-significant three-way interaction, $F(6,891)=0.389, p<.88$, shown by a 2 (factual, counterfactual) by 3 (epistemic, modal deontic, non-modal deontic) by 4 (modus ponens, modus tollens, denial of the antecedent, and affirmation of the consequent) ANOVA with repeated measures on the last factor on the endorsements of conclusions. The ANOVA also showed significant main effects of type of content, $F(2,297)=3.314, p<.04$, and type of inference, $F(3,891)=51.07, p<.0000$, and the latter two factors interacted, $F(6,891)=7.02, p<.0000$. None of the other effects was reliable.
} 
TABLE 4

The log transformed latencies (ms) to endorse the conclusions for indicative and subjunctive conditionals based on epistemic, modal deontic, and non-modal deontic content in Experiment 2

\begin{tabular}{lcccc}
\hline & $M P$ & $A C$ & $M T$ & $D A$ \\
\hline $\begin{array}{l}\text { Epistemic } \\
\text { Indicative }\end{array}$ & 9.317 & 9.394 & 9.423 & 9.285 \\
Subjunctive & 9.584 & 9.415 & 9.645 & 9.415 \\
$\begin{array}{l}\text { Deontic modal } \\
\text { Indicative }\end{array}$ & 9.235 & 9.219 & 9.162 & 9.154 \\
Subjunctive & 9.595 & 9.657 & 9.547 & 9.223 \\
$\begin{array}{l}\text { Deontic non-modal } \\
\text { Indicative }\end{array}$ & & & & \\
Subjunctive & 9.221 & 9.374 & 9.214 & 9.133 \\
\hline & 9.312 & 9.590 & 9.545 & 9.161 \\
\hline
\end{tabular}

$\mathrm{MP}=$ modus ponens, $\mathrm{AC}=$ affirmation of the consequent, $\mathrm{MT}=$ modus tollens, $\mathrm{DA}=$ denial of the antecedent.

Participants took the same amount of time to endorse the conclusion for each of the four inferences from subjunctives and indicatives, for the epistemic, modal deontic, and non-modal deontic conditionals, as Table 4 shows. ${ }^{4}$

The second experiment replicates the results of the first experiment and extends them to deontic conditionals with and without an explicit modal. Once again, the results corroborate our suggestion that deontic conditionals are represented in an initial set of models that makes explicit what is permissible and what is not permissible. The more explicit representation is constructed regardless of whether or not the deontic conditional employs an explicit modal auxilliary such as "must", and the representation for deontic conditionals is similar for indicative and subjunctive conditionals, both with a modal and without.

\section{GENERAL DISCUSSION}

Deontic conditionals are different from epistemic ones. People understand an indicative epistemic by initially keeping in mind one explicit possibility, the conjecture. But they understand an indicative deontic by initially keeping in mind

\footnotetext{
${ }^{4}$ These 12 comparisons were computed by simple effects $t$-tests on the non-significant threeway interaction, $F(6,345)=0.45, p<.85$, in an ANOVA on the log-transformed latencies for endorsements of conclusions. The ANOVA showed a main effect of conditional, $F(1,115)=5.05$, $p<.03$, and inference, $F(3,345)=2.74, p<.04$, but not of content. None of the variables interacted.
} 
two explicit possibilities, the conjecture, and the possibility ruled out by the conditional, e.g., "if the nurse cleaned up the blood then she must have worn rubber gloves":

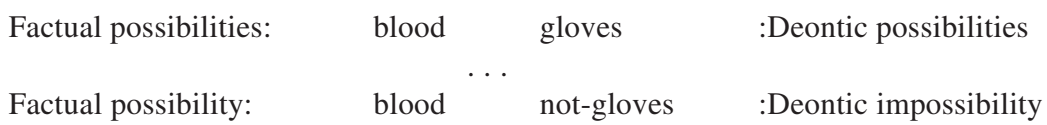

(Johnson-Laird \& Byrne, 2002). As a result, reasoners make more of the MT inference from conditionals that contain deontic content compared to epistemic content, but not more of the other three inferences, as our first experiment showed, and they do so whether or not the conditionals contain a modal auxiliary "must", as the second experiment showed.

Subjunctive deontic conditionals are also different from subjunctive epistemic ones. People understand a subjunctive epistemic by initially keeping in mind two explicit possibilities, the conjecture, and the presupposed facts. As a result they make more of the negative inferences, MT and DA, which require access to the presupposed facts, from a subjunctive than from an indicative (Byrne \& Tasso, 1999). But they understand a subjunctive deontic in exactly the same way as an indicative deontic, by initially keeping in mind two explicit possibilities, the conjecture and the possibility ruled out by the conditional. As a result, reasoners make MT and DA as often from a subjunctive deontic as from an indicative deontic, as the first experiment showed, and they do so whether or not the deontic conditional contains a modal auxillary "must", as the second experiment showed.

In summary, we corroborated two sets of predictions in the two experiments:

(1) Reasoners make more MT inferences from deontic conditionals. They do not make more MP and AC and DA inferences.

(2) Reasoners make MT and DA as often from a subjunctive as from an indicative conditional for deontic content (as well as the same amount of MP and $\mathrm{AC}$ ).

In this study we have provided a first attempt to understand conditionals that are both deontic and subjunctive, and our conclusion is that people may understand subjunctive deontic conditionals in a very similar way to indicative deontic conditionals.

Our predictions were derived from our view that reasoners construct models of possibilities (Johnson-Laird \& Byrne, 1991, 2002). An alternative view of conditional reasoning is that people rely on rules of inference and construct mental derivations of conclusions akin to logical proofs (e.g., Rips, 1994; Braine \& O'Brien, 1991); or they rely on stored rules of inference, which may be contained within domain-specific schema dedicated to situations of permission and obligation (e.g., Cheng \& Holyoak, 1985; Holyoak \& Cheng, 1995), or they 
may be contained within an innate deontic reasoning module evolved for violations of social contracts and hazard management (Cosmides \& Tooby, 1992; Fiddick, Cosmides, \& Tooby, 2000; Gigerenzer \& Hug, 1992). However, reasoning well need not depend on situations that elicit permission or precaution rules, or "checking for cheaters" and "checking for endangerment" strategies, but rather on situations that clarify relevant counterexamples (Girotto et al., 2001; Liberman \& Klar, 1996; Love \& Kessler, 1995; Sperber, Cara, \& Girotto, 1995; Sperber \& Girotto, in press). We suggest that when people understand a deontic conditional they keep in mind not only what is permitted but also what is not permitted. Familiarity with the rule, or knowledge of its context and the linguistic expression, such as "must" can help to ensure that what is impermissible is readily available.

People use their knowledge to modulate the meaning of a conditional: content and context can modulate the meaning of deontic conditionals to allow 10 distinct interpretations of them, including conditional and biconditional interpretations, tautological and reverse conditional (or enabling) interpretations, disabling interpretations and so on (see Johnson-Laird \& Byrne, 2002, for details). When a deontic conditional is interpreted as a biconditional, e.g., "if you tidy your room then you may go out to play" (Manktelow \& Over, 1991), there are two situations that are not permissible, e.g., tidying the room and not being allowed out to play, and not tidying the room and going out to play (Johnson-Laird \& Byrne, 1992, 1995). People may keep both counterexamples in mind (Politzer \& NguyenXuan, 1992) or just one or the other depending on whose perspective they take, e.g., a mother or a child (Manktelow \& Over, 1991; Fairley, Manktelow, \& Over, 1999; Light, Girotto, \& Legrenzi, 1990).

In our experiments we examined deontic rules in the past tense. Deontic rules in the present tense, e.g., "if the nurse cleans blood then she must wear rubber gloves", clearly refer to repeated events and generally can be rephrased using "every time...", although repetition is not an essential feature of them, e.g., "if the world comes to an end, you must not panic" refers to a single unique event. Deontic rules in the past tense, e.g., "if the nurse cleaned blood then she must have worn rubber gloves", seem to pinpoint a specific event. Uniqueness is not an essential feature of them, however, e.g., the translation of "if a man dies, his wife has to be buried with him" to the past tense, "if a man died in ancient times, his wife had to be buried with him" retains its reference to repeated events. Nonetheless, past tense deontic rules can seem inferential or forensic in nature; the consequent can seem to report an inference that the speaker has made. Although it has been shown that the frequency of inferences does not differ as a function of past or present tense for indicative epistemic conditionals (Schaeken, Schroyens, \& Dieussaert, 2001), and for subjunctive epistemics (Byrne \& Tasso, 1999), we do not yet know whether the frequency of inferences from deontic conditionals differs as a function of tense and the question awaits future research. 
We have shown that when deontic conditionals about common social rules are phrased in the subjunctive mood, they are not interpreted as counterfactual, unlike epistemic conditionals. Can subjunctive deontic conditionals be counterfactual? We believe the answer is that they can, but their counterfactuality depends on more than the subjunctive mood-in particular it depends on knowledge of the content or context of the rule. Someone who utters a subjunctive deontic such as, "if you had tossed heads, you would have had to forfeit your winnings", may mean one of two things. They may mean that the facts are that you did not toss heads, but if you had, the rule that you forfeit your winnings would have applied. The subjunctive mood in this case can convey a presupposition that the antecedent is false (you did not toss heads) but it does not convey the presupposition that the consequent is false, factually or deontically. But a second meaning is possible if the speaker and hearer share knowledge, for example, if the utterance is made in the context of a game whose rules have changed. In that case, the subjunctive mood and the knowledge or context can convey not only presuppositions about what once was possible and is so no longer (tossing heads), but also presuppositions about what once was obligatory but is so no longer (forfeiting). We suggest that counterfactual deontic conditionals depend on more than linguistic mood.

Subjunctive deontic conditionals are an important and unique sort of conditional which has not been examined before, despite the fact that people often generate counterfactual thoughts that spontaneously focus on violations of social regulations (e.g., McCloy \& Byrne, 2000; N'gbala \& Branscombe, 1995). This first investigation of subjunctive deontics indicates that they can shed light on the nature of reasoning with both deontic conditionals and counterfactual conditionals.

\section{REFERENCES}

Braine, M.S.D., \& O'Brien, D.P. (1991). A theory of If: A lexical entry, reasoning program, and pragmatic principles. Psychological Review, 98, 182-203.

Byrne, R.M.J., Espino, O., \& Santamaría, C. (1999). Counterexamples and the suppression of inferences. Journal of Memory and Language, 40, 347-373.

Byrne, R.M.J., \& McEleney, A. (2000) Counterfactual thinking about actions and failures to act. Journal of Experimental Psychology: Learning, Memory, and Cognition, 26, 1318-1331.

Byrne, R.M.J., \& Quelhas, A.C. (1999). Raciocínio contrafactual e modelos mentais. Análise Psicológica, 4, 713-721.

Byrne, R.M.J., Segura, S., Culhane, R., Tasso, A., \& Berrocal, P. (2000). The temporality effect in counterfactual thinking about what might have been. Memory \& Cognition, 28, 264-281.

Byrne, R.M.J., \& Tasso, A. (1999) Deductive reasoning with factual, possible, and counterfactual conditionals. Memory \& Cognition, 27, 726-740.

Cheng, P.N., \& Holyoak, K.J. (1985). Pragmatic reasoning schemas. Cognitive Psychology, 17, 391-416. 
Cosmides, L., \& Tooby, J. (1992). Cognitive adaptations for social exchange. In J. Barkow, L. Cosmides, \& J. Tooby (Eds.), The adapted mind. New York: Oxford University Press.

Dudman, V.H. (1988). Indicative and subjunctive. Analysis, 48, 113-122.

Evans, J.St.B.T., Newstead, S., \& Byrne, R.M.J. (1993). Human reasoning: The psychology of deduction. Hove, UK: Lawrence Erlbaum Associates Ltd.

Fairley, N., Manktelow, K.I., \& Over, D.E. (1999). Necessity, sufficiency and perspective effects in causal conditional reasoning. Quarterly Journal of Experimental Psychology, 52A, 771-790.

Fiddick, L., Cosmides, L., \& Tooby, J. (2000). No interpretation without representation: The role of domain-specific representations and inferences in the Wason selection task. Cognition, 77, $1-79$.

Fillenbaum, S. (1974). Information amplified: Memory for counterfactual conditionals. Journal of Experimental Psychology, 102, 44-49.

Gigerenzer, G., \& Hug, K. (1992). Domain specific reasoning: Social contracts, cheating, and perspective change. Cognition, 43, 127-171.

Girotto, V., Gilly, M., Blaye, A., \& Light, P. (1989). Children's performance in the selection task: plausibility and familiarity. British Journal of Psychology, 80, 79-95.

Girotto, V., Kemmelmeier, M., Sperber, D., \& Van der Henst, J.-B. (2001). Inept reasoners or pragmatic virtuosos? Relevance and the deontic selection task. Cognition, 81, B69-B76.

Girotto, V., Legrenzi, P., \& Rizzo, A. (1991). Event controllability in counterfactual thinking. Acta Psychologia, 78, 111-133.

Girotto, V., Mazzocco, A., \& Cherubini, P. (1992). Judgements of deontic relevance in reasoning: A reply to Jackson and Griggs. Quarterly Journal of Experimental Psychology, 45A, 547-574.

Griggs, R.A., \& Cox, J.R. (1983). The effects of problem content and negation on Wason's selection task. Quarterly Journal of Experimental Psychology, 35A, 519-533.

Holyoak, K.J., \& Cheng, P. (1995). Pragmatic reasoning with a point of view. Thinking and Reasoning, 1, 289-313.

Johnson-Laird, P.N., \& Byrne, R.M.J. (1991). Deduction. Hove, UK: Lawrence Erlbaum Associates Ltd.

Johnson-Laird, P.N., \& Byrne, R.M.J. (1992). Modal reasoning, models, and Manktelow and Over. Cognition, 43, 173-182.

Johnson-Laird, P.N., \& Byrne, R.M.J. (1995). A model point of view. Thinking and Reasoning, 1, 339-350.

Johnson-Laird, P.N., \& Byrne, R.M.J. (2002). Conditionals: A theory of meaning, pragmatics, and inference. Psychological Review, 109, 646-678.

Johnson-Laird, P.N., Byrne, R.M.J., \& Schaeken, W. (1992). Propositional reasoning by model. Psychological Review, 99, 418-439.

Kahneman, D., \& Miller, D. (1986). Norm theory: Comparing reality to its alternatives. Psychological Review, 93, 136-153.

Kahneman, D., \& Tversky, A. (1982). The simulation heuristic. In D. Kahneman, P. Slovic, \& Tversky (Eds.), Judgement under uncertainty: Heuristic and biases (pp. 201-208). New York:Cambridge University Press.

Lewis, D. (1973). Counterfactuals. Cambridge, MA: Harvard University Press.

Liberman, N., \& Klar, Y. (1996). Hypothesis testing in Wason's selection task: Social exchange, cheating detection, or task understanding. Cognition, 58, 127-156.

Light, P.H., Girotto, V., \& Legrenzi, P. (1990). Children's reasoning on conditional promises and permissions. Cognitive Development, 5, 369-383.

Love, R.E., \& Kessler, C.M. (1995). Focusing in Wason's selection task: Content and instruction effects. Thinking \& Reasoning, 1, 153-182.

Manktelow, K.I., \& Fairley, N. (2000). Superordinate principles in reasoning with causal and deontic conditionals. Thinking and Reasoning, 6, 41-66.

Manktelow, K.I., \& Over, D.E. (1990). Deontic thought and the selection task. In K.J. Gilhooly, 
M.T.G. Keane, R.H. Logie, \& G. Erdos (Eds.), Lines of thinking: reflections on the psychology of thought (Vol. 1). Chichester, UK: John Wiley \& Sons.

Manktelow, K.I., \& Over, D.E. (1991). Social roles and utilities in reasoning with deontic conditionals. Cognition, 39, 85-105.

McCloy, R., \& Byrne, R.M.J. (2000). Counterfactual thinking about controllable events. Memory \& Cognition, 28, 1071-1078.

McCloy, R., \& Byrne, R.M.J. (2002). Semifactual “even if” thinking. Thinking and Reasoning, 8, 41-67.

Miller, D.T., \& Gunasegaram, S. (1990).Temporal order and the perceived mutability of events: Implications for blame assignment. Journal of Personality and Social Psychology, 59, 11111118.

Moreno-Ríos, S., García-Madruga, J.A., \& Byrne, R.M.J. (2002). Semifactual and counterfactual conditionals. Manuscript submitted for publication.

N'gbala A., \& Branscombe N. R. (1995). Mental simulation and causal attribution: When simulating an event does not affect fault assignment. Journal of Experimental Social Psychology, 31, 139-62.

Politzer, G., \& Nguyen-Xuan, A. (1992). Reasoning about conditional promises and warnings: Darwinian algorithms, mental models, relevance judgements or pragmatic schemas? Quarterly Journal of Experimental Psychology, 44, 401-412.

Quelhas, A.C. \& Byrne, R.M.J. (2000). Counterfactual conditionals: Reasoning latencies. In J.A. García-Madruga, N. Carriedo, and M.J. González-Labra (Eds) Mental models in reasoning (pp 315-326). Madrid: UNED.

Rips, L.J. (1994). The psychology of proof. Cambridge, MA: MIT Press.

Schaeken, W., Schroyens, W., \& Dieussaert, K. (2001). Conditional assertions, tense, and explicit negatives. European Journal of Cognitive Psychology, 13(4), 433-450.

Segura, S., Fernandez-Berrocal, P., \& Byrne, R.M.J. (2002). Temporal and causal order effects in counterfactual thinking. Quarterly Journal of Experimental Psychology, 55A, 1295-1305.

Sperber, D., Cara, F., \& Girotto, V. (1995). Relevance theory explains the selection task. Cognition, 52, 3-39.

Sperber, D., \& Girotto, V. (in press). Response to Fiddick, Cosmides, and Tooby. Cognition.

Stalnaker, R.C. (1968). A theory of conditionals. In N. Rescher (Ed.), Studies in logical theory. American Philosophical Quarterly Monograph, 2. Oxford: Blackwell.

Thompson, V.A., \& Byrne, R.M.J. (in press). Counterfactual reasoning: Making inferences about things that didn't happen. Journal of Experimental Psychology: Learning, Memory, and Cognition.

Wells, G.L., Taylor, B.R., \& Turtle, J.W. (1987). The undoing of scenarios. Journal of Personality and Social Psychology, 53, 421-430.

Winer, B. J. (1971). Statistical principles in experimental design. New York: McGraw-Hill. 


\section{APPENDIX}

The indicative versions of each conditional (with the subjunctive versions in parentheses).

\section{English translations}

\section{Materials for Experiment 1}

\section{Epistemic}

If Rute was (had been) in Coimbra then Cristina was (would have been) in Lisboa.

If Ana was (had been) in Porto then Joao was (would have been) in Braga.

If Pedro was (had been) in Faro then Rui was (would have been) in Beja.

If Alfonso was (had been) in Tavira then Leonor was (would have been) in Olhao.

\section{Deontic}

If he drove (had driven) the car then he (would have) fastened the seat belt.

If he drove (had driven) the car at night then he (would have) turned the headlights on.

If he drove (had driven) the car on the motorway then he drove (would have driven) at more than $40 \mathrm{~km} / \mathrm{h}$.

If he drove (had driven) the car then he (would have) drunk alcohol-free beer.

\section{Materials for Experiment 2}

\section{Epistemic}

If Rute was (had been) in Coimbra then Cristina was (would have been) in Lisboa.

If Ana was (had been)in Porto then Joao was (would have been) in Braga.

If Pedro was (had been)in Faro then Rui was (would have been) in Beja.

\section{Deontic with modal}

If the nurse (had) cleaned up the blood then she must have worn (must have had to wear) rubber gloves.

If the courier (had) travelled by motorcycle then he must have worn (must have had to wear) a helmet.

If the tourist went (had gone) deep sea diving then she must have taken (must have had to take) a diving course.

\section{Deontic without modal}

If the nurse (had) cleaned up the blood then she wore (would have worn) rubber gloves.

If the courier (had) travelled by motorcycle then he wore (would have worn) a helmet.

If the tourist went (had gone) deep sea diving then she took (would have taken) a diving course.

\section{Original Portuguese}

Materials for Experiment 1

\section{Epistemic}

Se a Rute esteve (tivesse estado) em Coimbra, então a Cristina esteve (teria estado) em Lisboa. Se a Ana esteve (tivesse estado) no Porto, então o João esteve (teria estado) em Braga. Se o Pedro esteve (tivesse estado) em Faro, então o Rui esteve (teria estado) em Beja. Se o Afonso esteve (tivesse estado) em Tavira, então a Leonor esteve (teria estado) em Olhão. 


\section{Deontic}

Se ele conduziu (tivesse conduzido) o carro, então usou (teria usado) o cinto de segurança. Se ele conduziu (tivesse conduzido) o carro de noite, então ligou (teria ligado) os faróis.

Se ele conduziu (tivesse conduzido) o carro na auto-estrada, então circulou (teria circulado) a mais de $40 \mathrm{Km} / \mathrm{h}$.

Se ele conduziu (tivesse conduzido) o carro, então bebeu (teria bebido) cerveja sem alcool.

\section{Materials for Experiment 2}

\section{Epistemic}

Se a Rute esteve (tivesse estado) em Coimbra, então a Cristina esteve (teria estado) em Lisboa.

Se a Ana esteve (tivesse estado) no Porto, então o João esteve (teria estado) em Braga.

Se o Pedro esteve (tivesse estado) em Faro, então o Rui esteve (teria estado) em Beja.

\section{Deontic with modal}

Se a enfermeira limpou (tivesse limpo) o sangue, então teve de usar (teria de ter usado) luvas de borracha.

Se o mensageiro viajou (tivesse viajado) de mota, então teve de usar (teria de ter usado) um capacete.

Se a turista fez (tivesse feito) mergulho no mar, então teve de fazer (teria de ter feito) um curso de mergulho.

\section{Deontic without modal}

Se a enfermeira limpou (tivesse limpo) o sangue, então usou (teria usado) luvas de borracha. Se o mensageiro viajou (tivesse viajado) de mota, então usou (teria usado) um capacete.

Se a turista fez (tivesse feito) mergulho no mar, então fez (teria feito) um curso de mergulho. 


Copyright of Thinking \& Reasoning is the property of Taylor \& Francis Ltd and its content may not be copied or emailed to multiple sites or posted to a listserv without the copyright holder's express written permission. However, users may print, download, or email articles for individual use. 
Copyright of Thinking \& Reasoning is the property of Taylor \& Francis Ltd and its content may not be copied or emailed to multiple sites or posted to a listserv without the copyright holder's express written permission. However, users may print, download, or email articles for individual use. 